Article

\title{
Biosynthesis of Silver Nanoparticles Using Brown Marine Macroalga, Sargassum Muticum Aqueous Extract
}

\author{
Susan Azizi $^{1, *}$, Farideh Namvar ${ }^{2,3}$, Mahnaz Mahdavi ${ }^{4, *}$, Mansor Bin Ahmad ${ }^{1}$ \\ and Rosfarizan Mohamad ${ }^{2,5}$
}

1 Department of Chemistry, Faculty of Science, Universiti Putra Malaysia, 43400 UPM Serdang, Selangor, Malaysia; E-Mail: mansorahmad@upm.edu.my

2 Institute of Tropical Forestry and Forest Products (INTROP), Universiti Putra Malaysia, 43400 UPM Serdang, Selangor, Malaysia; E-Mail: farideh.namvar@gmail.com;

3 Department of Medicine, Applied Biology Research Centre, Mashhad Branch, Islamic Azad University, Mashhad 917568, Iran

4 Department of Chemistry, Faculty of Science, Shiraz Branch, Islamic Azad University, Shiraz 71993-3, Iran

5 Department of Bioprocess Technology, Faculty of Biotechnology and Biomolecular Sciences, Universiti Putra Malaysia, 43400 UPM Serdang, Selangor, Malaysia;

E-Mail: farizanmohd@gmail.com

* Authors to whom correspondence should be addressed; E-Mails: azisusan@gmail.com (S.A.); mahnaz.chem@gmail.com (M.M.); Tel.: +601-7622-8029 (S.A.); +601-2211-7882 (M.M.).

Received: 25 September 2013; in revised form: 28 October 2013 / Accepted: 8 November 2013 / Published: 18 December 2013

\begin{abstract}
Biological synthesis of nanoparticles is a relatively new emerging field of nanotechnology which has economic and eco-friendly benefits over chemical and physical processes of synthesis. In the present work, for the first time, the brown marine algae Sargassum muticum (S. muticum) aqueous extract was used as a reducing agent for the synthesis of nanostructure silver particles (Ag-NPs). Structural, morphological and optical properties of the synthesized nanoparticles have been characterized systematically by using FTIR, XRD, TEM and UV-Vis spectroscopy. The formation of Ag-NPs was confirmed through the presence of an intense absorption peak at $420 \mathrm{~nm}$ using a UV-visible spectrophotometer. A TEM image showed that the particles are spherical in shape with size ranging from 5 to $15 \mathrm{~nm}$. The nanoparticles were crystalline in nature. This was confirmed by the XRD pattern. From the FTIR results, it can be seen that the reduction has mostly been carried out by sulphated polysaccharides present in S. muticum.
\end{abstract}


Keywords: silver nanoparticles; Sargassum muticum; marine algae; biosynthesis

\section{Introduction}

In the fields of nanoscience and nanotechnology, the largest activity has been focused on the synthesis of new nanoparticles with different sizes and new shapes, which have strong effects on their widely varying properties. Nanoparticles are attracting increasing attention due to their unusual and fascinating properties, which are strongly influenced by their size, morphology and structure [1].

Nanoparticles (NPs) are small in diameter, but large in surface area, and are important to many current exclusive medical and industrial applications such as biological engineering, catalysts, and electronic devices [2]. Currently, a large number of physical, chemical, biological, and hybrid methods are available to synthesize different types of nanoparticles [3]. Though physical and chemical methods are more popular for nanoparticle synthesis, the use of toxic compounds limits their applications. To overcome the problem of toxicity in synthesis, safe eco-friendly green methods have a major role for producing nanoparticles [4]. Several methods have been used for the green synthesis of NPs using various biological materials as reducing agents such as microorganisms, marine organisms, micro-fluids, and plant extracts [5-9]. Among the most important bioreductants are plant extracts, which are relatively easy to handle, readily available, low cost, and have been well explored for the green synthesis of other nanomaterials [10]. Moreover, the biologically active molecules involved in the green synthesis of NPs act as functionalizing ligands, making these NPs more suitable for biomedical applications [11]. Marine algae are well-known as functional food for their richness in lipids, minerals and certain vitamins, and also several bioactive substances like polysaccharides, proteins and polyphones, with potential medicinal uses against cancer, oxidative stress, inflammation, allergy, thrombosis, lipidemia, hypertensive and other degenerative diseases [12-18]. Thus, their phytochemicals include hydroxyl, carboxyl, and amino functional groups, which can serve both as effective metal-reducing agents and as capping agents to provide a robust coating on the metal nanoparticles in a single step [19].

Silver nanoparticles have been widely used during the past few years in various applications due to their well-known effectiveness in biomedical [20], electronic [21], catalysis [22] and optical applications [23]. In particular, the outstanding antimicrobial properties of Ag-NPs have led to the development of a wide variety of nanosilver products, including nanosilver-coated wound dressings, contraceptive devices, surgical instruments, and implants [24,25]. Apart from these antimicrobial activities, Ag-NPs are also known to possess antifungal, anti-inflammatory, antiviral, anti-angiogenesis, and antiplatelet properties [26,27]. Additionally, more recent developments have seen Ag-NPs used in room spray, wallpaper gloves, laundry detergent, and wall paint formulations as well as in the textile industry for clothing manufacturing [28,29].

The present study describes a single step, green, and rapid synthesis of silver nanoparticles (Ag-NPs) prepared by biological (green) techniques using Sargassum muticum (S. muticum). These green-synthesized nanoparticles were examined by ultraviolet-visible spectroscopy (UV-Vis), 
transmission electron microscopy (TEM), powder X-ray diffraction (XRD) and Fourier transform infrared (FTIR) spectroscopy to determine their size and shape.

\section{Results and Discussion}

The formation of silver nanoparticles was confirmed through visual assessment. The reaction mixture turned to dark brown color from brownish-yellow color within 20 min indicated the synthesis of silver nanoparticles (Figure 1). The appearance of dark brown color may be due to the excitation of surface plasmon resonance (SPR) effect and reduction of $\mathrm{AgNO}_{3}$ [30].

Figure1. The aqueous extract of S. muticum (a) before; and (b) after synthesis of Ag-NPs.

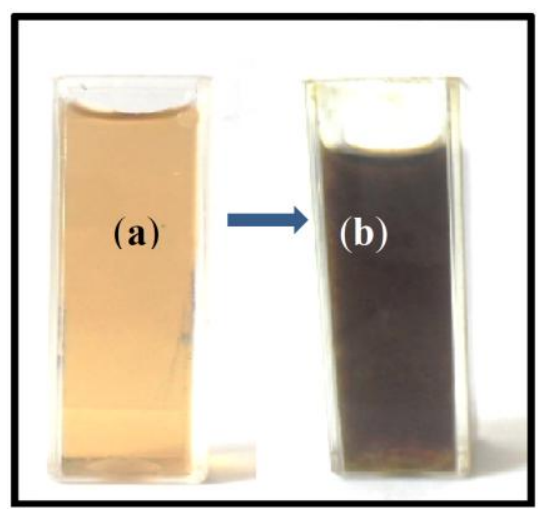

Characterization of Ag Nanoparticles

$\mathrm{UV}-\mathrm{Vis}$ spectrum of reaction mixture at different wavelengths ranging from 300 to $700 \mathrm{~nm}$ showed strong absorption peak with centering at $420 \mathrm{~nm}$ (Figure 2) indicated the formation of Ag-NPs. This absorption is close to that seen for silver nanoparticles formed by different methods [31]. The wide absorption peak may be induced by the wide size distribution of Ag nanoparticles.

Figure 2. UV-Visible spectrum of (a) S. muticum aqueous extract; and (b) S. muticum formed Ag-NPs.

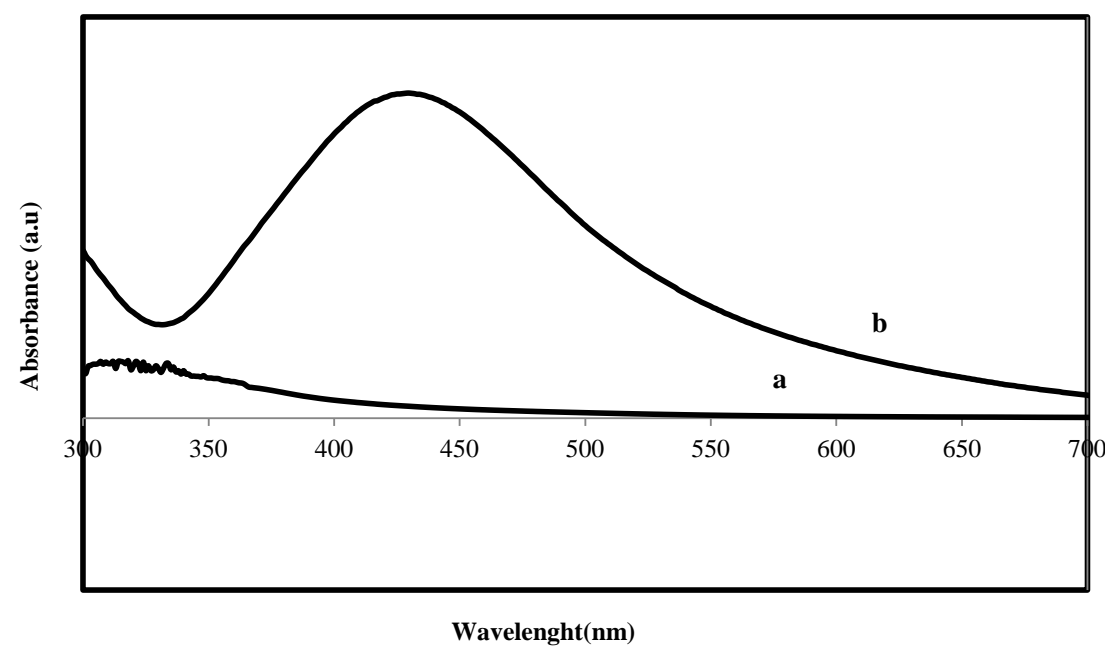


The FT-IR spectra were used to identify the possible biomolecules responsible for the reduction of the $\mathrm{Ag}^{+}$ions and capping of the $S$. muticum formed Ag-NPs.

Figure 3 shows the FTIR spectra of S. muticum aqueous extract and bio-synthesized Ag-NPs.

In the FTIR spectrum of $S$. muticum, the signal at $1235 \mathrm{~cm}^{-1}$ corresponded to asymmetric stretching vibration of a sulphate and band at $1021 \mathrm{~cm}^{-1}$ attributed to symmetric $\mathrm{C}-\mathrm{O}$ vibration associated with a $\mathrm{C}-\mathrm{O}-\mathrm{SO}_{3}$ [32] or the $\mathrm{C}-\mathrm{OH}$, which disappeared after synthesis of Ag-NPs. This specified the involvement of sulfate or hydroxyl groups in the reduction process of Ag-NPs. In addition, the peaks at $3217 \mathrm{~cm}^{-1}$ (OH stretching) and $2929 \mathrm{~cm}^{-1}$ (CH stretching) were also detected. After reduction of $\mathrm{AgNO}_{3}$, the decreases in intensity at $3217 \mathrm{~cm}^{-1}$ imply the involvement of the $\mathrm{OH}$ groups in the reduction process. This is further confirmed with a reduction in $\mathrm{PH}$ of solution during the reaction. The above peaks generally occur in polysaccharides indicating the participation of sulfated polysaccharides in the synthesis of Ag NPs. This is in agreement with our previous studies, which showed that the sulfated polysaccharides present in $S$. muticum had strong ability to synthesis of $\mathrm{Fe}_{3} \mathrm{O}_{4}$ [19] and $\mathrm{ZnO}$ [33] nanoparticles. Similarly, Venkatpurwar and Pokharkar's (2011) [34] reported that sulfated polysaccharides isolated from the marine alga Porphyra vietnamensis (Rhodophyta) had a strong capacity to synthesize Ag NPs.

The peaks at $1415 \mathrm{~cm}^{-1}$ indicate the $\mathrm{C}-\mathrm{C}$ groups derived from aromatic rings that are present in the S. muticum aqueous extract. Another peak at $1610 \mathrm{~cm}^{-1}$ is attributed to the stretching vibration of (NH) $\mathrm{C}=\mathrm{O}$ group that is characteristic of proteins shifted from $1610 \mathrm{~cm}^{-1}$ and became shorter after synthesis of Ag-NPs, indicating a member of $(\mathrm{NH}) \mathrm{C}=\mathrm{O}$ group within the cage of cyclic peptides is involved in synthesizing and capping the nanoparticles. In the FTIR spectrum of S. muticum, Ag-NPs were formed. The additional peaks at 2466, 1788, 1375, 705, and $391 \mathrm{~cm}^{-1}$ are related to Ag-NPs. We propose the presence of vander waals forces of interaction between nitrogen and oxygen atoms in bio-compounds present in S. muticum and Ag-NPs. Therefore, the FT-IR results imply that the Ag-NPs were successfully synthesized and capped with bio-compounds present in the $S$. muticum extract by using a green method.

Figure 3. FT-IR spectrum for (a) the S. muticum a queous extract; and (b) S. muticum formed Ag-NPs.

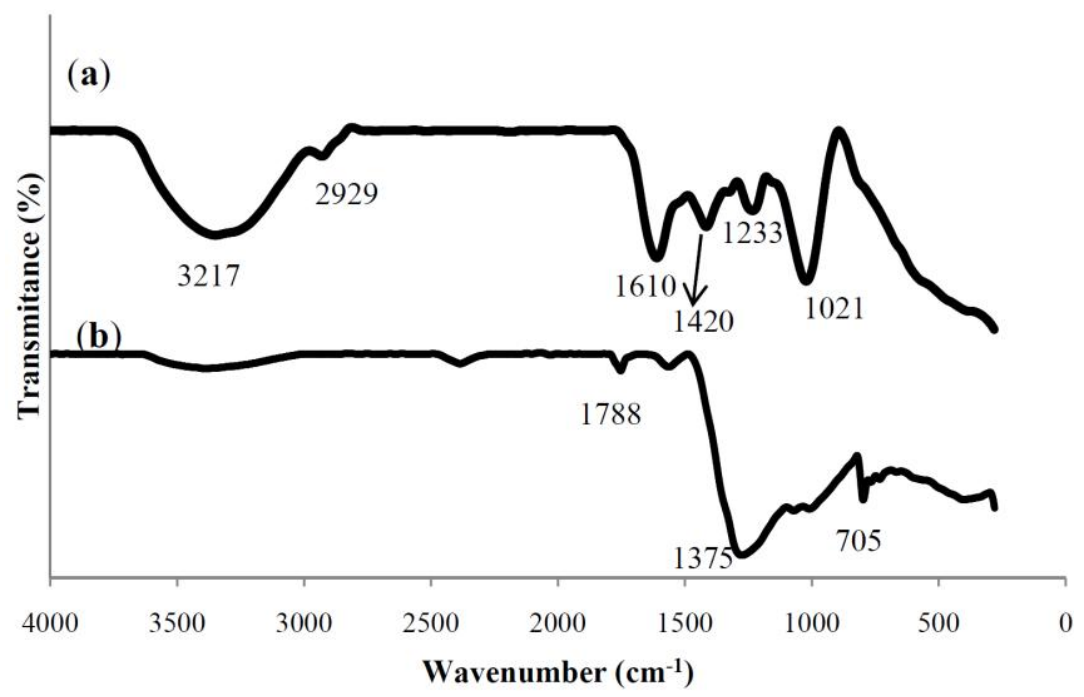


The XRD pattern (Figure 4) shows that the particles are crystalline with small size. The lattice planes (111), (200), (220), and (311) were identified with the corresponding Bragg's angles of $37.95^{\circ}$, $45.84^{\circ}, 64.07^{\circ}$, and $76.43^{\circ}$, respectively, which confirm the face-centered cubic structure of the formed Ag-NPs. The size of formed silver nanoparticles was estimated by using Scherrer's equation [35] by determining the width of the (111) Bragg reflection and was calculated to be around $8 \mathrm{~nm}$.

Figure 4. X-ray diffraction pattern of bio-synthesized Ag-NPs.

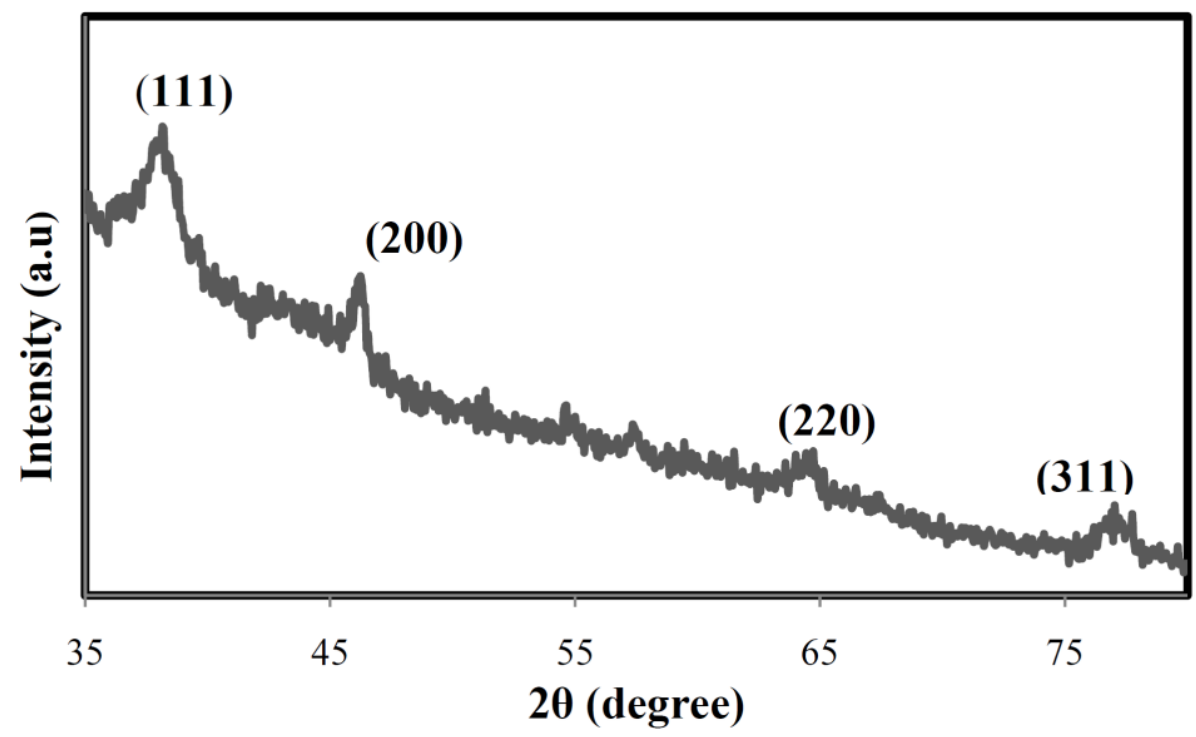

The TEM image Figure 5a and particle size distribution graph Figure 5b show the Ag-NPs formed were well dispersed with a spherical structures and particle size ranging from 5 to $15 \mathrm{~nm}$ with some deviations. Control of the size and structure of the resultant nanoparticles can be related to the interactions between bio-compounds such as polysaccharides, proteins, polyphenols and phenolic compounds and metal atoms [36].

Figure 5. The (a) TEM micrograph; and (b) particle size distributions of bio-synthesized Ag-NPs.

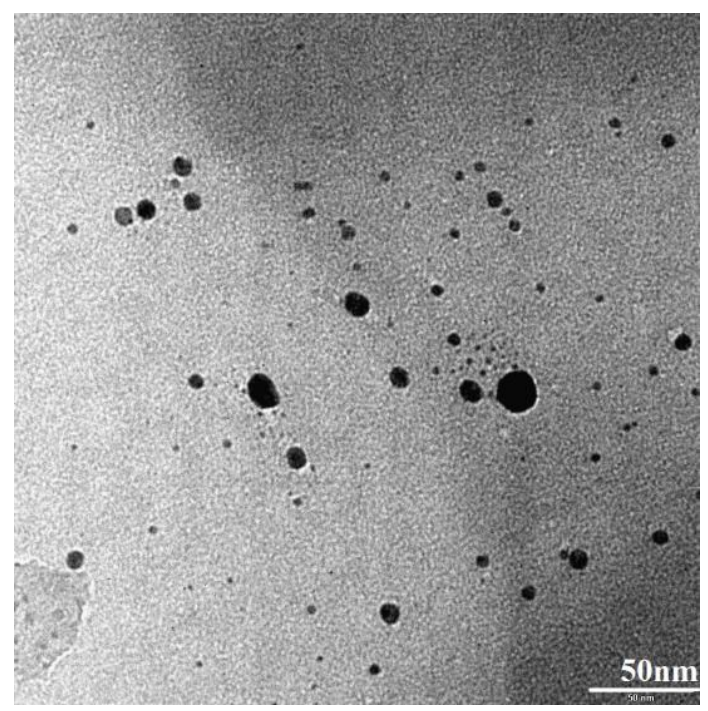

(a)

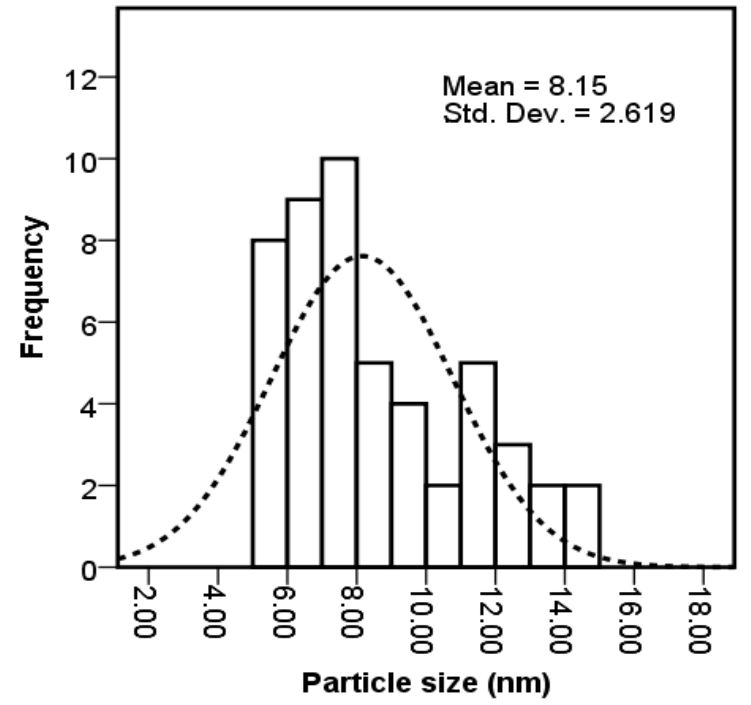

(b) 


\section{Experimental Section}

\subsection{Materials}

Specimens of the brown marine algae S. muticum from the coastal areas of Persian Gulf waters were collected and washed carefully with distilled water. The clean marine alga was freeze dried at $-20{ }^{\circ} \mathrm{C}$ and then, crushed into powder.

$\mathrm{AgNO}_{3}$ (99.98\%) was used as silver precursor and it was supplied from Merck (Darmstadt, Germany). All the solutions were prepared with deionized water.

\subsection{Preparation of S. muticum Extracts}

Powder marine alga $S$. muticum sample $(1 \mathrm{~g})$ was dispersed in $100 \mathrm{~mL}$ distilled water by magnetic stirring and heated at $100{ }^{\circ} \mathrm{C}$ for $20 \mathrm{~min}$. The extract was filtered through mesh, followed by Millipore filter $(0.2 \mu \mathrm{m})$, and stored at $-20^{\circ} \mathrm{C}$ before use.

\subsection{Biosynthesis of Ag-NPs}

The Erlenmeyer flask containing $50 \mathrm{~mL}$ of aqueous solution $(1 \mathrm{mM})$ of $\mathrm{AgNO}_{3}$ was reacted with $50 \mathrm{~mL}$ of the aqueous extract of $S$. muticum for $30 \mathrm{~min}$ under continuous stirring at $35{ }^{\circ} \mathrm{C}$ and then allowed to stand at room temperature for another $2 \mathrm{~h}$. Initial $\mathrm{PH}$ of solution was about 7.5 which changed to 5.6 at the end of the reaction. The dark brown solid product was collected through centrifugation at $6000 \mathrm{rpm}$ for $10 \mathrm{~min}$ and careful washing with distilled water. The final products were obtained by drying at room temperature. The resulting dried sample was crushed into powder and stored in an air tight container for further analysis.

\subsection{Characterization of Ag-NPs}

Phase purity and particle size were determined by X-ray diffraction (XRD) analysis recorded by diffractometer (XPERT-PRO) with nickel-filtered $\mathrm{Cu}(\lambda=1.542 \AA)$ at room temperature and the instrument was operated at $40 \mathrm{kv}$ and $30 \mathrm{~mA}$. The powder sample with smooth surface was mounted on sample holder, and the measurement was carried out at $10^{\circ}-70^{\circ}$. The chemical structure was examined by using FTIR spectrometer (Perkin-Elmer 1725X, Waltham, MA, USA). FTIR spectra of the solution samples were studied with a resolution of $4.0 \mathrm{~cm}^{-1}$ at room temperature using a $\mathrm{KBr}$ disc containing $1.0 \mathrm{mg}$ of the sample and $0.1 \mathrm{mg}$ of the fine grade $\mathrm{KBr}$ at wavenumber range from 400 to $4000 \mathrm{~cm}^{-1}$. The shape, size and microstructures of the sample were characterized using a HITACHI H-700 transmission electron microscope (Hitachi, Ltd., Tokyo, Japan) with an acceleration voltage of $120 \mathrm{kV}$ at room temperature. TEM samples were prepared by dispersing small quantities of the dried sample into distillated water and depositing a few drops of the resulting suspension on a copper grid. Size distribution and the average size of 80 nanoparticles were estimated on the basis of three TEM images with the assistance of Sigma-Scan Pro software (SPSS IBM, Statistics 20, IBM Corporation, Endicott, NY, USA). The sample solutions were analyzed at room temperature for UV-Visible absorption using UV-Vis spectrophotometer (a Lambda 25-Perkin Elmer, Waltham, MA, USA). The absorbance spectra were scanned in the range of $200-800 \mathrm{~nm}$ with a $1 \mathrm{~nm}$ interval at room temperature. 


\section{Conclusions}

In this study, a simple, ecofriendly and economic biological procedure has been developed to synthesize Ag-NPs. The Ag-NPs were synthesized by bio-reduction of silver ions using the brown marine algae $S$. muticum aqueous extract. The biosynthesized silver nanoparticles have spherical shapes and the particle size ranges from 5 to $15 \mathrm{~nm}$ with a mean size of $8 \mathrm{~nm}$. The FTIR spectra revealed the involvement of sulfate and hydroxyl moieties of polysaccharide in the formation of Ag-NPs. The biosynthesized silver nanoparticles are expected to have remarkable applications in pharmaceutical and biomedical fields.

\section{Acknowledgments}

The authors are grateful to staff of the Department of Chemistry UPM (UNIVERSITY PUTRA MALAYSIA) for their technical assistance, and UNIVERSITY PUTRA MALAYSIA for the research grant RUGS 9199840.

\section{Conflicts of Interest}

The authors declare no conflict of interest.

\section{References}

1. Gopalakrishnan, K.; Ramesh, C.; Ragunathan, V.; Thamilselvan, M. Antibacterial activity of $\mathrm{Cu}_{2} \mathrm{O}$ nanoparticles on E.coli synthesized from tridax procumbens leaf extract and surface coating with polyaniline. Dig. J. Nanomater. Biostructure 2012, 7, 833-839.

2. Darroudi, M.; Zak, A.M.; Muhamad, M.R.; Huang, N.M.; Hakimi, M. Green synthesis of colloidal silver nanoparticles by sonochemical method. Mater. Lett. 2012, 66, 117-120.

3. Mahdavi, M.; Ahmad, M.B.; Haron, M.J.; Namvar, F.; Nadi, B.; Ab Rahman, M.Z.; Amin, J. Synthesis, surface modification and characterisation of biocompatible magnetic iron oxide nanoparticles for biomedical applications. Molecules 2013, 18, 7533-7548.

4. Arockiya Aarthi Rajathi, F.; Parthiban, C.; Ganesh Kumar, V.; Anantharaman, P. Biosynthesis of antibacterial gold nanoparticles using brown alga, stoechospermum marginatum (kützing). Spectrochim. Acta Part A Mol. Biomol. Spectrosc. 2012, 99, 166-173.

5. Shameli, K.; Ahmad, M.B.; Zamanian, A.; Sangpour, P.; Shabanzadeh, P.; Abdollahi. Y.; Zargar, M. Green biosynthesis of silver nanoparticles using Curcuma longa tuber powder. Int. J. Nanomed. 2012, 7, 5603-5610.

6. Govindaraju, K.; Kiruthiga, V.; Kumar, V.G.; Singaravelu, G. Extracellular synthesis of silver nanoparticles by a marine alga, Sargassum wightii Grevilli and their antibacterial effects. J. Nanosci. Nanotechnol. 2009, 9, 5497-5501.

7. Saifuddin, N.; Wong, C.W.; Yasumira, A.A.N.E. Rapid biosynthesis of silver nanoparticles using culture supernatant of bacteria with microwave irradiation. E. J. Chem. 2009, 6, 61-70.

8. Bhainsa, K.C.; D’Souza, S.F. Extracellular biosynthesis of silver nanoparticles using the fungus Aspergillus fumigatus. Colloids Surf. B. Biointerf. 2006, 47, 160-164. 
9. Willner, I.; Basnar, B.; Willner, B. Nanoparticle-enzyme hybrid systems for nanobiotechnology. FEBS J. 2007, 4, 302-309.

10. Khan, M.; Khan, M.; Adil, S.F.; Tahir, M.N.; Tremel, W.; Alkhathlan, H.Z.; Al-Warthan, A.; Siddiqui, M.R. Green synthesis of silver nanoparticles mediated by Pulicaria glutinosa extract. Int. J. Nanomed. 2013, 8, 1507-1516.

11. Lu, A.H.; Salabas, E.L.; Schüth, F. Magnetic nanoparticles: Synthesis, protection, functionalization, and application. Angew. Chem. 2007, 46, 1222-1244.

12. Namvar, F.; Suhaila, M.; Fard, S.G.; Behravan, J. Polyphenol-rich seaweed (Eucheuma cottonii) extract suppresses breast tumour via hormone modulation and apoptosis induction. Food Chem. 2012, 130, 376-382.

13. Zuercher, A.W.; Fritsché, R.; Corthésy, B.; Mercenier, A. Food products and allergy development, prevention and treatment. Curr. Opin. Biotechnol. 2006, 17, 198-203.

14. Perez, G.R.M.; Zavala, S.M.; Perez, G.S.; Perez, G.C. Antidiabetic effect of compounds isolated from plants. Phytomedicine 1998, 5, 55-75.

15. Nishino, T.; Fukuda, A.; Nagumo, T.; Fujihara, M.; Kaji, E. Inhibition of the generation of thrombin and factor Xa by a fucoidan from the brown seaweed Ecklonia kurome. Thromb. Res. 1999, 96, 37-49.

16. Miyashita, K. The carotenoid fucoxanthin from brown seaweed affects obesity. Lipid Technol. 2009, 21, 186-190.

17. Mohamed, S.; Hashim, S.N.; Rahman, H.A. Seaweeds: A sustainable functional food for complementary and alternative therapy. Trends Food Sci. Technol. 2012, 23, 83-96.

18. Wada, K.; Nakamura, K.; Tamai, Y. Seaweed intake and blood pressure levels in healthy pre-school Japanese children. Nutr. J. 2011, 10, 83-88.

19. Mahdavi, M.; Namvar, F.; Ahmad, M.B.; Mohamad, R. Green biosynthesis and characterization of magnetic iron oxide $\left(\mathrm{Fe}_{3} \mathrm{O}_{4}\right)$ nanoparticles using seaweed (Sargassum muticum) aqueous extract. Molecules 2013, 18, 5954-5964.

20. Cao, X.L.; Cheng, C.; Ma, Y.L.; Zhao, C.S. Preparation of silver nanoparticles with antimicrobial activities and the researches of their biocompatibilities. J. Mater. Sci. Mater. Med. 2010, 21, 2861-2868.

21. Mohan, Y.M.; Lee, K.J.; Premkumar, T.; Geckeler, K.E. Hydrogel networks as nanoreactors: A novel approach to silver nanoparticles for antibacterial applications. Polymer 2007, 48, 158-164.

22. Feng, X.; Qi, X.; Li, J.; Yang, L.W.; Qiu, M.C.; Yin, J.J.; Lu, F.; Zhong, J.X. Preparation structure and photo-catalytic performances of hybrid $\mathrm{Bi}_{2} \mathrm{SiO}_{5}$ modified Si nanowire arrays. Appl. Surf. Sci. 2011, 257, 5571-5575.

23. Hayward, R.C.; Saville, D.A.; Aksay, I.A. Electrophoretic assembly of colloidal crystals with optically tunable micropatterns. Nature 2000, 404, 56-59.

24. Lohse, S.E.; Murphy, C.J. Applications of colloidal inorganic nanoparticles: From medicine to energy. J. Am. Chem. Soc. 2012, 134, 15607-15620.

25. You, C.; Han, C.; Wang, X.; Zheng Y.; Li, Q.; Hu, X.; Sun, H. The progress of silver nanoparticles in the antibacterial mechanism, clinical application and cytotoxicity. Mol. Biol. Rep. 2012, 39, 9193-9201. 
26. Monteiro, D.R.; Silva, S.; Negri, M.; Gorup, L.F.; de Camargo, E.R.; Oliveira, R.; Barbosa, D.B.; Henriques, M. Silver nanoparticles: Influence of stabilizing agent and diameter on antifungal activity against Candida albicans and Candida glabrata biofilms. Lett. Appl. Microbiol. 2012, 54, 383-391.

27. Martínez-Gutierrez, F.; Thi, E.P.; Silverman, J.M.; de Oliveira, C.C.; Svensson, S.L.; Vanden Hoek, A.; Sánchez, E.M.; Reiner, N.E.; Gaynor, E.C.; Pryzdial, E.L.; et al. Antibacterial activity, inflammatory response, coagulation and cytotoxicity effects of silver nanoparticles. Nanomedicine 2012, 8, 328-336.

28. Park, M.; Im, J.; Shin, M.; Min, Y.; Park, J.; Cho, H.; Park, S.; Shim, M.-B.; Jeon, S.; Chung, D.-Y.; et al. Highly stretchable electric circuits from a composite material of silver nanoparticles and elastomeric fibres. Nat. Nanotechnol. 2012, 7, 803-809.

29. Gottesman, R.; Shukla, S.; Perkas, N.; Solovyov, L.A.; Nitzan, Y.; Gedanken, A. Sonochemical coating of paper by microbiocidal silver nanoparticles. Langmuir 2011, 27, 720-726.

30. Mulvaney, P. Surface plasmon spectroscopy of nanosized metal particles. Langmuir 1996, 12, 788-800.

31. Lee, Ch.J.; Karim, M.R.; Vasudevan, T.; Kim, H.J.; Raushan, K.; Jung, M.J.; Kim, D.Y.; Lee, M.S. A comparison method of silver nanoparticles prepared by the gamma irradiation and in situ reduction methods. Bull. Korea Chem. Soc. 2010, 31, 1993-1996.

32. Camara, R.B.G.; Costa, S.L.; Fidelis, G.P. Heterofucans from the brown seaweed canistrocarpus cervicornis with anticoagulant and antioxidant activities. Marine Drugs 2011, 9,124-138.

33. Azizi, S.; Ahmad, M.B.; Namvar, F.; Mohamad, R. Green biosynthesis and characterization of zinc oxide nanoparticles using brown marine macroalga Sargassum muticum aqueous extract. Mater. lett. 2014, 116, 275-277.

34. Venkatpurwar, V.; Pokharkar, V. Green synthesis of silver nanoparticles using marine polysaccharide: Study of in-vitro antibacterial activity. Mater. Lett. 2011, 65, 999-1002.

35. Shen, L.M.; Bao, N.Z.; Yanagisawa, K. Direct synthesis of $\mathrm{ZnO}$ nanoparticles by a solution-free mechanochemical reaction. Nanotechnology 2006, 17, 5117-5123.

36. Shao, Y.; Jin, Y.; Dong, S. Synthesis of gold nanoparticles by aspartate reduction of gold chloride. Chem. Commun. 2004, 9, 1104-1105.

(C) 2013 by the authors; licensee MDPI, Basel, Switzerland. This article is an open access article distributed under the terms and conditions of the Creative Commons Attribution license (http://creativecommons.org/licenses/by/3.0/). 